\title{
A TEORIA INSTITUCIONAL NA PESQUISA EM CONTABILIDADE: UMA REVISÃO
}

\author{
Institutional theory in accounting research: a review
}

\author{
Tiago de Moura Soeiro* \\ Cláudio de Araújo Wanderley**
}

\section{RESUMO}

Este estudo analisou os avanços e tendências das pesquisas em Contabilidade que utilizam como base teórica a Teoria Institucional por meio de uma revisão sistemática da literatura nos principais periódicos de Contabilidade brasileiros (entre 0 Qualis A1 e B2) e internacionais (grades 3 e 4 da Association of Business Schools - ABS). Ao todo foram analisados 135 artigos (32 brasileiros e 103 internacionais). Os artigos foram classificados de acordo com tópicos de pesquisa definido em estudos anteriores. A pesquisa contribuiu com a análise das tendências no uso da Teoria Institucional em na pesquisa contabilidade, e apresentou uma discussão sobre uma agenda de pesquisa futura. Desta forma, o estudo proporcionou uma análise sistemática e informativa da literatura contábil baseada na Teoria Institucional que pode expandir o entendimento, o debate e o uso de tal Teoria como lente teórica para a explicação de fenômenos complexos na área de Contabilidade.

Palavras-chave: Teoria Institucional; Investigação em Contabilidade; Revisão Sistemática.

\section{ABSTRACT}

The aim of this paper is to analyze the new directions and tendencies of research in Accounting that draws on the Institutional theory. Thus, in other to achieve this objective, a systematic literature review was carried out using the main Accounting journals in Brazil (Qualis A1, A2 and B2 journals) and internationally (ABS (2010) list grades 3 and 4 journals). 135 articles (32 Brazilian and 103 international papers) were analyzed. These papers were classified according to the research topics identified in previous studies. This paper contributes to the analysis of trends in the use of the Institutional Theory in Accounting research, as well as discussing a research agenda for the future. As a result, our study provides a systematic and informative analysis of the accounting literature based on the Institutional Theory that might expand the understanding, the debate and the use of such theory as a theoretical lens for the explanation of complex phenomena in the field of Accounting.

Keywords: Institutional Theory; Accounting Research; Systematic Review.

\footnotetext{
* Doutorando do Programa de Pós-Graduação em Ciências Contábeis da Universidade Federal de Pernambuco (UFPE). Mestre em Ciências Contábeis pela Universidade Federal de Pernambuco. E-mail: mourasoeiro@gmail. com. ORCID: 0000-0003-3576-2569

** Professor do Programa de Pós-Graduação em Ciências Contábeis da Universidade Federal de Pernambuco (UFPE). Ph.D. em Accounting pela University of Sheffield. E-mail: claudiowanderley@hotmail.com. E-mail: gatoledosilva@gmail.com. ORCID: 0000-0002-4559-176X
} 


\section{INTRODUÇÃO}

$\mathrm{P}$ esquisa é um processo de descoberta intelectual o qual tem o potencial de transformar o nosso conhecimento e entendimento do mundo (RYAN; SCAPENS; THEOBALD, 2002). Dentro da pesquisa em Contabilidade, de um modo geral, a pesquisa tem o objetivo fundamental de descoberta, interpretação e comunicação do conhecimento. Nos últimos anos, a pesquisa em Contabilidade vem registrando um crescimento significativo (PARKER; NORTHCOTT, 2016), em razão do interesse de pesquisadores, professores e estudantes que buscam analisar os fenômenos e as mudanças que têm ocorrido nessa área de conhecimento.

Wanderley e Cullen (2013) apontam que dentre os paradigmas alternativos de pesquisa em Contabilidade (pesquisa interpretativista e crítica), a Teoria Institucional vem ganhando popularidade, sendo assim, uma das mais utilizadas dentre as teorias consideradas alternativas ao funcionalismo. Uma das razões para a popularidade dessa teoria é que ela apresenta explicações para os processos pelos quais estruturas, incluindo esquemas, regras, normas e rotinas, se estabelecem como diretrizes autorizadas para o comportamento social (SCAPENS, 2006).

Portanto, a Teoria Institucional tem sido a corrente principal nas pesquisas alternativas em Contabilidade e Gestão (COOPER; PARKES; BLEWITT, 2014; ZUCCOLOTTO; SILVA; EMMENDOERFER, 2010), sendo aplicada para explicar o processo de legitimação nas organizações e no entendimento dos padrões e processos de mudança organizacional, por enfatizar o papel das regras e convenções que influenciam na maneira como as organizações e sociedade se comportam.

Apesar de sua principal aplicação se dar na Contabilidade Gerencial, esta teoria também pode ser utilizada como abordagem em outros campos da Contabilidade, a exemplo da Contabilidade Societária (ALON; DWYER, 2014; HASSAN; RANKIN; LU, 2014), Contabilidade Pública (ANTIPOVA; BOURMISTROV, 2013; MODELL, 2012; PALERMO, 2014), Contabilidade Social e Ambiental (CONTRAFATTO, 2014; CONTRAFATTO; BURNS, 2013) e Auditoria (ALLEYNE; HUDAIB; PIKE, 2013; FUNNELL; WADE, 2012) sendo utilizada para entender a regulação da Contabilidade, os padrões de Contabilidade internacional, decisões sobre adoção de normas internacionais e evidenciação.

Os constantes desenvolvimentos e temáticas estudadas pela abordagem institucional na Contabilidade, mencionados anteriormente, elucidam a potencialidade da aplicação e o poder explicativo da Teoria Institucional. Entretanto, apesar dessa grande popularidade, ao serem buscados artigos sobre a produção acadêmica em contabilidade com a utilização da referida teoria ${ }^{1}$, não foram identificados estudos, tanto a nível nacional quanto internacional, que sistematizassem de forma integrada como essa literatura está sendo aplicada nos campos da Contabilidade.

Desta forma, estudos anteriores como de Moll, Burns e Major (2006) estão desatualizados, e tampouco consideraram a extensão da literatura - focados apenas em questões

1. Foi realizado uma busca booleana utilizando os termos: institucional; contabilidade; e Revisão ou Bibliometria, ou blibliométrico, ou Produção. Também foram buscados seus respectivos termos em inglês. 
mais clássicas, não atentando para que diferentes componentes da Teoria Institucional expliquem como as regras, normas, rotinas, estruturas e esquemas são criadas, difundidas, adotadas e adaptadas ao longo do espaço e do tempo; e como eles caem em declínio e desuso. Além disso, a utilização da Teoria Institucional na pesquisa nacional está aumentando e, apesar dos esforços de busca, conforme mencionado anteriormente, não foram identificados estudos que consolidem esta abordagem.

Assim, nosso estudo busca analisar os avanços e tendências das pesquisas em Contabilidade que utilizam como base teórica a Teoria Institucional, respondendo ao seguinte questionamento: quais são os avanços e tendências das investigações em Contabilidade que aplicam o paradigma institucional, no período de 2009 e 2016 ?

Para atingir este objetivo, este artigo foi estruturado como uma revisão sistemática da literatura. Desta forma, esta pesquisa descreve e aglutina o conhecimento existente na literatura sobre Teoria Institucional de modo a identificar aspectos relevantes, tais como o desenvolvimento das linhas de pesquisas do institucionalismo organizacional em Contabilidade e contextos das investigações, dentre outras características que são exploradas mais adiante no trabalho.

Além desta parte introdutória, que contextualiza o tema e define o propósito e alcance da pesquisa, o presente estudo contempla a revisão da literatura sobre a pesquisa institucional (seção 2), a descrição dos procedimentos metodológicos (seção 3), os resultados e discussões da revisão sistemática (seção 4), os direcionamentos para futuras investigações (seção 5) e as considerações finais (seção 6).

\section{LINHAS DA PESQUISA INSTITUCIONAL EM CONTABILIDADE}

A Teoria Institucional é geralmente subdividida em três vertentes: New Institutional Economics (NIE); Old Institutional Economics (OIE); e New Institutional Sociology (NIS).

A NIE é uma vertente que faz parte do corpo teórico da Economia Neoclássica. Desta forma, ela possui os princípios base da modelização econômica: agentes racionais com funções e objetivos definidos. A NIE propõe o desenvolvimento dos modelos econômicos, introduzindo pressupostos ou variáveis que levam em consideração o contexto organizacional (SCAPENS, 2006).

A OIE questiona alguns pressupostos da economia neoclássica (MAJOR; RIBEIRO, 2009), tais como a racionalidade individual e o individualismo metodológico ao se analisar o desenvolvimento e mudança que se processam nos sistemas sociais. Esta vertente leva em consideração a ação dos agentes econômicos que estão atuando num contexto social, em que as normas e valores sociais moldam os comportamentos individuais (MAJOR; RIBEIRO, 2009). A OIE também defende o holismo metodológico ao considerar que intituições e organizações existem em ambientes complexos, cuja consideração global (e não parcial ou simplista) deve estar envolvida na análise.

Por fim, a NIS enfoca as organizações dentro de uma grande rede de relacionamentos entre as organizações e sistemas culturais. 0 ambiente institucional não apenas influencia o relacionamento das organizações com o mercado, mas também suas crenças, 
normas e tradições (DIMAGGIO; POWELL, 1983; MEYER; ROWAN, 1977). Além do mais, o ambiente institucional é caracterizado pela elaboração de regras, práticas, símbolos, crenças e requerimentos normativos aos quais indivíduos e organizações precisam se conformar para receber apoio e legitimidade. Um dos princípios básicos da NIS é o de que a estrutura organizacional é o resultado das pressões exercidas pelo meio envolvente em que as instituições operam.

Partindo destas vertentes, a revisão elaborada por Moll, Burns e Major (2006) selecionou as pesquisas que utilizaram estas abordagens para posteriormente classificá-las com relação aos assuntos. A primeira linha de investigação que foi destacada pelos autores, foi a influência das forças macro institucionais nos sistemas contábeis das organizações, que está focado em estudo como as forças institucionais podem influenciar nas práticas intra-organizacionais. Isto é, o processo pelo qual os fatores do nível sociedade (ou macro) colidem com o comportamento organizacional (ou nível micro).

Moll, Burns e Major (2006), classificam nesta linha os estudos focados nas forças institucionais que podem influenciar nas práticas intra-organizacionais. Alguns estudos dedicaram seus esforços a investigar a mudança na utilização de sistemas de avaliação de desempenho (ver por exemplo: HUSSAIN; HOQUE, 2002, HUSSAIN; GUNASEKARAN, 2002) e a configuração de padrões e relatórios financeiros (MEZIAS; SCARSELLETTA, 1994).

Outros estudos dedicaram-se a estudar o princípio fundamental das teorias institucionais, ao estudar e melhorar o entendimento do como os ambientes institucionais são formados. Dando origem a segunda linha de pesquisa: a estruturação do Campo Organizacional. Nestes estudos investiga-se como as organizações afetam seus ambientes, e dependência da instituição dentro do campo organizacional para sua construção e força. Desta forma, entende-se que há dualidade entre organização e seu ambiente institucional.

Assim, os estudos dedicam-se a melhorar o entendimento sobre como os ambientes institucionais são formados (ANSARI; EUSKE, 1987; CARPENTER; DIRSMITH, 1993). Neste contexto, quando as forças institucionais e sociopolíticas influenciam a introdução de uma mudança, a análise da estruturação do campo organizacional deve-se concentrar na institucionalização (BURNS; SCAPENS, 2000) e nas contradições institucionais (SEO; CREED, 2002) que explicam a mudança e os conflitos entre as instituições concorrentes.

A terceira linha de pesquisa, dedica-se a estudar a legitimidade e organizações. Estas investigações consideram que as organizações aderem a valores sociais mais amplos por razões de legitimidade, pela qual tais valores determinam a "adequação" do trabalho, arranjos e práticas organizacionais. Grande parte das pesquisas nesta área busca estudar os atributos de legitimação dos sistemas contábeis.

Muitos pensamentos institucionais são baseados na premissa de que as organizações aderem a valores sociais mais amplos por razões de legitimidade, pela qual tais valores determinam a "adequação" do trabalho, arranjos e práticas organizacionais. Devido a isto grande parte das pesquisas nessa área visam estudar os atributos de legitimação dos sistemas contábeis (ver por exemplo: ABERNETHY; CHUA, 1996).

A quarta linha dedica-se a estudar o papel da agência e poder na análise institucional, que leva em consideração que o ambiente institucional é caracterizado por uma 
gama de diferentes autoridades, cada um com suas expectativas sobre qual é o modo apropriado de operar. As múltiplas, e frequentemente conflitantes, expectativas que afetam a organização sugere que estas organizações não são passivas na escolha de seus arranjos e práticas. Ao contrário, sugere que a organização responde estrategicamente ao ambiente institucional (OLIVER, 1991). Estudos reconhecem essa possibilidade de ação estratégica da organização e tem investigado a implementação da mudança contábil modelada por cada perspectiva.

Burns (2000) analisa as características da complexidade e dinâmica da mudança na Contabilidade ao longo do tempo. Neste estudo é mostrado como a introdução de um novo procedimento contábil é provavelmente menos problemático quando a mudança é compatível com a com as regras, rotinas e padrões de pensar e fazer existentes dentro da organização (BURNS; SCAPENS, 2000). Contudo nas situações em que isso não se aplica, Burns (2000) mostra uma mobilização do poder e políticas como sendo importante para o eventual direcionamento e resultado da implementação da mudança.

Por fim, a Contabilidade e busca por eficiência que é a linha de pesquisa que é enraizada no paradigma da economia neoclássica. A perspectiva da NIE sobre a Contabilidade é mais restrita e específica que na OIE e NIS. A literatura da NIE na Contabilidade descreve a existência de configurações particulares de Contabilidade em razões de eficiência ou minimização de custos.

Esta linha descreve a existência de configurações particulares de Contabilidade em razões de eficiência ou minimização de custos. Por exemplo, Colbert e Spicer (1995) explanam sobre "temas gerais de Contabilidade (por exemplo desempenho e controle, responsabilidade e preço de transferência) em termo de escolhas ótimas entre alternativas em uma dada situação de transação. Contudo, destaca-se que a NIE associa a mudança na Contabilidade com referência para minimização de custos mudando de uma configuração ótima (ou equilíbrio) para outra.

\section{MÉTODO}

Realizamos uma revisão sistemática das pesquisas que utilizam a Teoria Institucional, de modo individual ou em conjunto, como plataforma teórica. Desta forma, a abordagem metodológica desta pesquisa foi baseada nos estudos de Shields (1997), Baxter e Chua (2003), Chenhall e Smith (2011), Moll, Burns e Major (2006), Hesford et al. (2006) e Hoque (2014), que contribuíram para a fundamentação das variáveis utilizadas nesta pesquisa. No que tange aos procedimentos da revisão sistemática e as categorias utilizadas na pesquisa, encontram-se sumarizados na Figura 1.

Inicialmente foi conduzida uma coleta dos artigos, diretamente no site dos periódicos eletrônicos que publicam artigos de Contabilidade. Buscando encontrar artigos relevantes e de boa qualidade, foram selecionados os periódicos melhores avaliados conforme as instituições competentes - a nível nacional o Qualis Capes, e a nível internacional a Association Business Schools (ABS). 
Começar com o Tema Geral: Teoria Institucional em Contabilidade

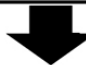

Objetivo da Revisão:

- Sintetizar e avaliar a investigação do passado

- Identificar ou construir lacunas na investigação existente

- Discutir direcionamentos para pesquisas futuras
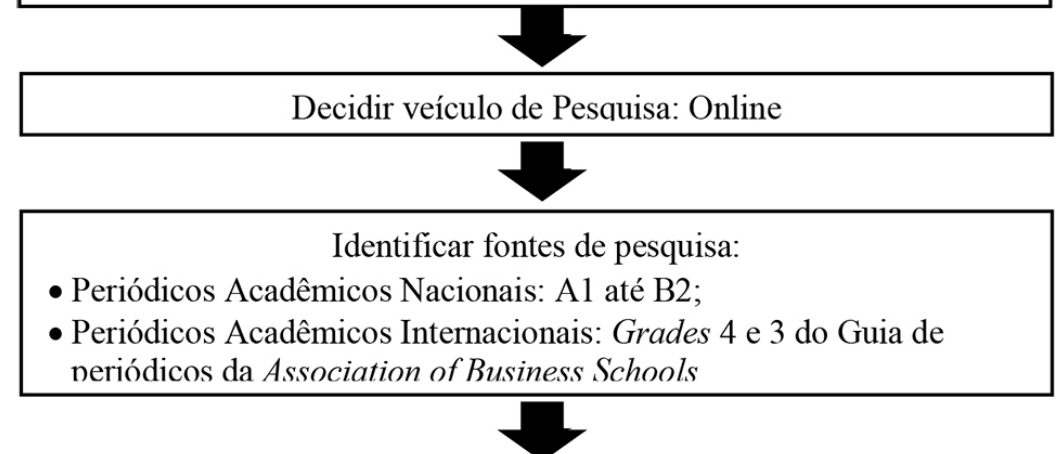

Linhas de Pesquisa;

Classificar pesquisas anteriores por:

- Teorias;

- Contexto/ambiente;

- Método de Pesquisa; e

- Técnica de Análise;

- Síntese dos achados

Avaliação Sistêmica dos artigos:

- Identificar lições aprendidas nas pesquisas analisadas

- Identificar lacunas e agendas de pesquisas futuras

- Concluir e esboçar limitações da Revisão

Figura 1 - Síntese do processo da revisão sistemática elaborada

Fonte: Elaboração própria (2017).

Para os periódicos nacionais, foi consultada a página do Qualis Capes, a partir da área de conhecimento de Administração, Ciências Contábeis e Turismo. A seleção dos periódicos se deu considerando os termos "contábil", "Contabilidade", "accounting", e sua inclusão no Qualis (2013), nos estratos A1, A2, B1 e B2. A escolha do Qualis deve-se a seu reconhecimento e uso na classificação das pesquisas no Brasil. Sendo assim, foram selecionadas 10 revistas brasileiras². Já para os periódicos a nível internacional foi escolhido

2. Revista Contabilidade \& Finanças (RCF); Contabilidade Vista \& Revista (RCVR); Revista de Contabilidade e Organizações (RCO); Revista Universo Contábil (RUC); Revista Contemporânea de Contabilidade da UFSC (RCC); Revista de Contabilidade, Gestão e Governança (RCGG); Revista de Contabilidade e Administração da Unisinos (BASE); Revista Enfoque: Reflexão Contábil (RERC); Revista de Administração, Contabilidade e Economia (RACE), e Advances in Scientific and Applied Accounting (ASAA). 
o Combined Journal Guide da Association of Business Schools (ABS, 2010). Foi selecionada a área correspondente a Accountancy, para identificar os periódicos específicos de Contabilidade. Desta forma, selecionados os estratos mais altos (grades 4 e 3). Com isso, foram selecionados 21 periódicos ${ }^{3}$. Contudo, foram encontrados artigos em nove periódicos brasileiros e 13 internacionais (ver Tabela 1).

No período compreendido entre 2009 e 2016 foram coletados 210 artigos (36 nacionais e 174 internacionais). Entretanto, destes foram analisados um total de 135 artigos (32 nacionais e 103 internacionais) e excluídos 75 artigos por não preencher os critérios básicos de seleção dos artigos: ser relacionado com Contabilidade e utilizar a Teoria Institucional como plataforma teórica (MODELL, 2009).

Para a classificação com relação as teorias os artigos foram inicialmente analisados com base na utilização de um modelo ou análise institucional por meio de uma ou mais vertentes da teoria, ou ainda realizaram uma combinação de perspectivas com outras teorias. Neste sentido, foi considerado a enunciação do posicionamento dos pesquisadores sobre a perspectiva utilizada como critério objetivo de classificação. Sendo assim, os artigos foram classificados, de acordo com a vertente da Teoria Institucional, em: Nova Economia Institucional; Velha Economia Institucional; Nova Sociologia Institucional; ou Multi-teórica quando houve a combinação de no mínimo duas das perspectivas anteriores, ou combinação de outras teorias à Teoria Institucional, em qualquer uma das vertentes (ver Tabela 2).

Para a classificação dos artigos por linhas de pesquisas (ver seção 2), foram utilizadas as mesmas previamente apresentadas no estudo de Moll, Burns e Major (2006). Contudo, durante as análises, foram identificados novos direcionamentos nas linhas de investigação em função da ampliação na utilização da teoria, ou também, a não cobertura na obra mencionada. Desta forma, os artigos foram classificados inicialmente nas seguintes categorias: Influência das forças macro institucionais nos sistemas contábeis; A Estruturação do Campo Organizacional; Legitimidade e Organizações; Agência e Poder na análise Institucional; ou Contabilidade como Configuração Eficiente (ver Tabela 3).

Além dessas duas classificações, os artigos também foram classificados utilizando as mesmas categorias baseadas nas obras de Shields (1997), Chenhall e Smith (2011), Hesford et al. (2006) e Hoque (2014). Assim, os trabalhos foram classificados com relação ao método da pesquisa: a) quantitativo: Análise Documental, Estudo de Campo, Estudo de Caso, Pesquisa Participativa; b) qualitativo: Analítica, Survey, Análise Documental, e Estudo de Campo; e c) métodos mistos: Análise Documental, Estudo de Caso, Analítico (ver Tabela 4).

Também foi construída uma síntese dos artigos utilizado uma abordagem adaptada de Baxter e Chua (2003) para sintetiza-los com base em contexto, objetivo, foco ou questão

3. Journal of Accounting Research (JAR); Journal of Accounting and Economics (JAE); Accounting Review (TAR); Accounting, Organizations and Society (AOS); Review of Accounting Studies (RAS); Contemporary Accounting Research (CAR); Abacus; Accounting and Business Research (ABR); Accounting Forum (TAF); Journal of Accounting Literature (JAL); European Accounting Review (EAR); Critical Perspectives on Accounting (CPA); Accounting, Auditing and Accountability Journal (AAAJ); British Accounting Review (BAR); Management Accounting Research (MAR); Financial Accountability and Management (FAM); Journal of Accounting and Public Policy (JAPP); International Journal of Accounting (IJA); Accounting Horizons (AH); Journal of Accounting, Auditing and Finance (JAAF); e Behavioral Research in Accounting (BRA). 
de pesquisa, metodologia, uso da teoria e contribuições. Para tal, foi procedida a leitura integral de todos os artigos a fim de identificar esses aspectos e construir uma matriz de síntese dos artigos.

Em seguida, depois de categorizados procedeu-se, seguindo as ideias de Hoque (2014), uma quantificação dos estudos por meio de matrizes que apresentam a ocorrência das variáveis analisadas ao longo do tempo. Este procedimento permitiu, através da criação de gráficos e tabelas interativas, a observação da evolução e frequência dos elementos analisados, como as tendências e novos direcionamentos nas pesquisas - por exemplo: com relação às escolhas metodológicas, lente teórica, ou contexto. Este procedimento é importante, pois, por meio dele é possível observar a densidade dos artigos com base nas escolhas dos investigadores, sintetizadas nas variáveis observadas neste estudo.

Por fim, os estudos foram agrupados com base nas suas respectivas linhas de investigação e analisados de modo a elucidar os direcionamentos e as lições apreendidas, limitações das mesmas e lacunas no conhecimento ou pontos ainda pouco explorados ou não claros. A revisão foi auxiliada pela utilização de um software de análise qualitativa, o ATLAS.ti 7, que auxiliou na organização e categorização dos artigos.

\section{RESULTADOS}

\subsection{BREVE ANÁLISE DESCRITIVA DOS RESULTADOS}

A Tabela 1 apresenta a quantidade de artigos analisados por revista ao longo do período em evidência. No período analisado observa-se que os periódicos que mais publicaram nesta temática são internacionais, representando $77,04 \%$ do total de artigos. As revistas que mais se destacam são a Critical Perspectives in Accounting, seguida pela Accounting, Auditing and Accountability e Accounting Organization and Society. No âmbito nacional, os periódicos brasileiros de maior destaque foram a Revista Base da Unisinos, seguida pela Revista Universo Contábil.

Tabela 1 - Frequência de artigos publicados com a Teoria Institucional

\begin{tabular}{c|c|c|c|c|c|c|c|c|c|c|c}
\hline PERÍODICOS & $\mathbf{2 0 0 9}$ & $\mathbf{2 0 1 0}$ & $\mathbf{2 0 1 1}$ & $\mathbf{2 0 1 2}$ & $\mathbf{2 0 1 3}$ & $\mathbf{2 0 1 4}$ & $\mathbf{2 0 1 5}$ & $\mathbf{2 0 1 6}$ & $\mathbf{T o t a l}$ & $\begin{array}{c}\text { Total } \\
\text { Individual } \\
(\%)\end{array}$ & $\begin{array}{c}\text { Total } \\
\text { Global (\%) }\end{array}$ \\
\hline NACIONAIS & $\mathbf{5}$ & $\mathbf{3}$ & $\mathbf{2}$ & $\mathbf{4}$ & $\mathbf{6}$ & $\mathbf{4}$ & $\mathbf{2}$ & $\mathbf{5}$ & $\mathbf{3 1}$ & $\mathbf{1 0 0}$ & $\mathbf{2 2 , 9 6}$ \\
\hline BASE & 1 & 1 & 1 & 1 & 2 & & & 1 & 7 & 22,58 & 5,19 \\
\hline RUC & 1 & & & & 1 & 2 & & 2 & 6 & 19,35 & 4,44 \\
\hline RC\&F & 2 & & & 2 & & & & & 4 & 12,9 & 2,96 \\
\hline RCO & 1 & 1 & & & 2 & & & & 4 & 12,9 & 2,96 \\
\hline RCV\&R & & 1 & & & & & 1 & 1 & 3 & 9,68 & 2,22 \\
\hline RCC & & & & & & 1 & 1 & 1 & 3 & 9,68 & 2,22 \\
\hline RCGG & & & 1 & & 1 & & & & 2 & 6,45 & 1,48 \\
\hline RACE & & & & & & 1 & & & 1 & 3,23 & 0,74 \\
\hline ASAA & & & & 1 & & & & & 1 & 3,23 & 0,74 \\
\hline
\end{tabular}




\begin{tabular}{c|c|c|c|c|c|c|c|c|c|c|c}
\hline PERÍODICOS & $\mathbf{2 0 0 9}$ & $\mathbf{2 0 1 0}$ & $\mathbf{2 0 1 1}$ & $\mathbf{2 0 1 2}$ & $\mathbf{2 0 1 3}$ & $\mathbf{2 0 1 4}$ & $\mathbf{2 0 1 5}$ & $\mathbf{2 0 1 6}$ & Total & $\begin{array}{c}\text { Total } \\
\text { Individual } \\
\text { (\%) }\end{array}$ & $\begin{array}{c}\text { Total } \\
\text { Global (\%) }\end{array}$ \\
\hline INTERNACIONAIS & $\mathbf{1 0}$ & $\mathbf{5}$ & $\mathbf{1 1}$ & $\mathbf{1 4}$ & $\mathbf{1 6}$ & $\mathbf{2 1}$ & $\mathbf{1 2}$ & $\mathbf{1 5}$ & $\mathbf{1 0 4}$ & $\mathbf{1 0 0}$ & $\mathbf{7 7 , 0 4}$ \\
\hline CPA & 2 & 3 & 2 & 1 & 1 & 5 & 3 & 3 & 20 & 19,23 & 14,81 \\
\hline AAAJ & 3 & & 3 & 3 & 4 & 4 & & & 17 & 16,35 & 12,59 \\
\hline AOS & & & & 4 & 3 & 2 & 2 & 4 & 15 & 14,42 & 11,11 \\
\hline BAR & & & & 1 & 2 & 3 & 2 & 3 & 11 & 10,58 & 8,15 \\
\hline TAF & & & 1 & 1 & 1 & 1 & 2 & 3 & 9 & 8,65 & 6,67 \\
\hline FAM & 3 & 1 & & 2 & 1 & 2 & & & 9 & 8,65 & 6,67 \\
\hline MAR & & 1 & 2 & 1 & 2 & & 1 & 1 & 8 & 7,69 & 5,93 \\
\hline CAR & & & 1 & & & 1 & 2 & 1 & 5 & 4,81 & 3,7 \\
\hline EAR & 1 & & 2 & & 1 & 1 & & & 5 & 4,81 & 3,7 \\
\hline IJA & & & & & & 2 & & & 2 & 1,92 & 1,48 \\
\hline Abacus & & & & & 1 & & & & 1 & 0,96 & 0,74 \\
\hline AH & 1 & & & & & & & & 1 & 0,96 & 0,74 \\
\hline BRA & & & & 1 & & & & & 1 & 0,96 & 0,74 \\
\hline Total & $\mathbf{1 5}$ & $\mathbf{8}$ & $\mathbf{1 3}$ & $\mathbf{1 8}$ & $\mathbf{2 2}$ & $\mathbf{2 5}$ & $\mathbf{1 4}$ & $\mathbf{2 0}$ & $\mathbf{1 3 5}$ & - & $\mathbf{1 0 0}$ \\
\hline
\end{tabular}

No que se refere ao uso das vertentes da Teoria Institucional, observa-se uma predominância nas abordagens sociológicas, ou seja, a NIS - ou sua combinação com outras teorias. De um modo geral, os modelos teóricos empregados nos artigos utilizam combinações de teorias de cunho econômico e sociológico para prover explicações mais holísticas do fenômeno em análise, conforme pode ser observado na Tabela 2.

Tabela 2 - Frequência de artigos com Teoria Institucional por corrente da teoria

\begin{tabular}{c|c|c|c|c|c|c|c|c|c|c}
\hline Vertente & $\mathbf{2 0 0 9}$ & $\mathbf{2 0 1 0}$ & $\mathbf{2 0 1 1}$ & $\mathbf{2 0 1 2}$ & $\mathbf{2 0 1 3}$ & $\mathbf{2 0 1 4}$ & $\mathbf{2 0 1 5}$ & $\mathbf{2 0 1 6}$ & Total & Total (\%) \\
\hline Multi-teórica & 11 & 6 & 8 & 12 & 18 & 16 & & 2 & 73 & 54,07 \\
\hline $\begin{array}{c}\text { Nova Sociologia } \\
\text { Institucional (NIS) }\end{array}$ & 2 & 1 & 1 & & 1 & 7 & 11 & 18 & 41 & 30,37 \\
\hline $\begin{array}{c}\text { Velha Economia } \\
\text { Institucional (OIE) }\end{array}$ & 2 & 1 & 4 & 6 & 3 & 1 & 2 & & 19 & 14,07 \\
\hline $\begin{array}{c}\text { Nova Economia } \\
\text { Institucional (NIE) }\end{array}$ & & & & & & 1 & 1 & & 2 & 1,48 \\
\hline Total & $\mathbf{1 5}$ & $\mathbf{8}$ & $\mathbf{1 3}$ & $\mathbf{1 8}$ & $\mathbf{2 2}$ & $\mathbf{2 5}$ & $\mathbf{1 4}$ & $\mathbf{2 0}$ & $\mathbf{1 3 5}$ & $\mathbf{1 0 0}$ \\
\hline
\end{tabular}

De acordo com a Tabela 3, as principais linhas de investigação são a Estruturação do campo Organizacional e a Influência de forças macro institucionais que moldam os sistemas contábeis. 
Tabela 3 - Frequência de artigos com Teoria Institucional por linha de pesquisa

\begin{tabular}{|c|c|c|c|c|c|c|c|c|c|c|}
\hline Linhas de Pesquisa & 2009 & 2010 & 2011 & 2012 & 2013 & 2014 & 2015 & 2016 & Total & Total (\%) \\
\hline $\begin{array}{l}\text { Agência e Poder na } \\
\text { Análise Institucional }\end{array}$ & 3 & 1 & 1 & 5 & 4 & 1 & 2 & 1 & 18 & 13,33 \\
\hline $\begin{array}{l}\text { Contabilidade e } \\
\text { Eficiência }\end{array}$ & & & 3 & 1 & 1 & 2 & 1 & 1 & 9 & 6,67 \\
\hline $\begin{array}{c}\text { Estruturação do Campo } \\
\text { Organizacional }\end{array}$ & 10 & 6 & 7 & 3 & 8 & 8 & 4 & 8 & 54 & 40 \\
\hline $\begin{array}{l}\text { Influência das Forças } \\
\text { Macro Institucionais }\end{array}$ & 2 & & 1 & 8 & 7 & 12 & 6 & 8 & 44 & 32,59 \\
\hline $\begin{array}{c}\text { Legitimidade e Organi- } \\
\text { zações }\end{array}$ & & 1 & 1 & 1 & 2 & 2 & 1 & 2 & 10 & 7,41 \\
\hline Total & 15 & 8 & 13 & 18 & 22 & 25 & 14 & 20 & 135 & 100 \\
\hline
\end{tabular}

Com relação às escolhas metodológicas, a Tabela 4 evidencia a predominância dos métodos qualitativos, em função dos problemas de pesquisa estarem preocupados na explicação e interpretação dos fenômenos, o que era esperado, pois esta é principal opção metodológica das investigações da corrente principal da Teoria Institucional que tem cunho sociológico. Porém, há condução de investigações quantitativas e mistas, que buscam identificar a presença dos elementos discutidos na Teoria Institucional, como o isomorfismo.

Tabela 4 - Frequência de artigos com Teoria Institucional por abordagem metodológica

\begin{tabular}{c|c|c|c|c|c|c|c|c|c|c}
\hline & $\mathbf{2 0 0 9}$ & $\mathbf{2 0 1 0}$ & $\mathbf{2 0 1 1}$ & $\mathbf{2 0 1 2}$ & $\mathbf{2 0 1 3}$ & $\mathbf{2 0 1 4}$ & $\mathbf{2 0 1 5}$ & $\mathbf{2 0 1 6}$ & Total & Total (\%) \\
\hline Qualitativa & $\mathbf{6}$ & $\mathbf{4}$ & $\mathbf{1 1}$ & $\mathbf{1 3}$ & $\mathbf{1 5}$ & $\mathbf{1 5}$ & $\mathbf{7}$ & $\mathbf{1 7}$ & $\mathbf{8 8}$ & $\mathbf{6 5 , 1 9}$ \\
\hline Análise Documental & 2 & & 1 & 2 & 1 & 2 & 2 & 4 & 14 & 10,37 \\
\hline Estudo de Campo & 1 & 1 & 3 & 5 & 4 & 7 & 3 & 5 & 29 & 21,48 \\
\hline Estudo de Caso & 3 & 3 & 6 & 6 & 10 & 5 & 2 & 8 & 43 & 31,85 \\
\hline Pesquisa Participativa & & & 1 & & & 1 & & & 2 & 1,48 \\
\hline Quantitativa & $\mathbf{5}$ & $\mathbf{0}$ & $\mathbf{1}$ & $\mathbf{3}$ & $\mathbf{2}$ & $\mathbf{5}$ & $\mathbf{7}$ & $\mathbf{2}$ & $\mathbf{2 5}$ & $\mathbf{1 8 , 5 2}$ \\
\hline Analítica & 2 & & 1 & 1 & 2 & 1 & 4 & 1 & 12 & 8,89 \\
\hline Survey & 3 & & & 2 & & 1 & & 1 & 7 & 5,19 \\
\hline Análise Documental & & & & & & 2 & 1 & & 3 & 2,22 \\
\hline Estudo de Campo & & & & & & 1 & 2 & & 3 & 2,22 \\
\hline Métodos Mistos & $\mathbf{0}$ & $\mathbf{1}$ & $\mathbf{0}$ & $\mathbf{1}$ & $\mathbf{1}$ & $\mathbf{1}$ & $\mathbf{0}$ & $\mathbf{0}$ & $\mathbf{4}$ & $\mathbf{2 , 9 6}$ \\
\hline Análise Documental & & 1 & & 1 & & & & & 2 & 1,48 \\
\hline Estudo de Caso & & & & & 1 & & & & 1 & 0,74 \\
\hline Analítico & & & & & & 1 & & & 1 & 0,74 \\
\hline Outros & $\mathbf{4}$ & $\mathbf{3}$ & $\mathbf{1}$ & $\mathbf{1}$ & $\mathbf{4}$ & $\mathbf{4}$ & $\mathbf{0}$ & $\mathbf{1}$ & $\mathbf{1 8}$ & $\mathbf{1 3 , 3 3}$ \\
\hline Total & $\mathbf{1 5}$ & $\mathbf{8}$ & $\mathbf{1 3}$ & $\mathbf{1 8}$ & $\mathbf{2 2}$ & $\mathbf{2 5}$ & $\mathbf{1 4}$ & $\mathbf{2 0}$ & $\mathbf{1 3 5}$ & $\mathbf{1 0 0}$ \\
\hline
\end{tabular}


Nas investigações analisadas observa-se uma pluralidade de técnicas de análise. As técnicas qualitativas para análise de dados se destacam sobre a análise narrativa e temática. Alguns estudiosos utilizaram técnicas menos usuais como análise etnográfica e poética. $\mathrm{Na}$ análise quantitativa, a técnica que predomina é regressão e correlação. Outras pesquisas realizaram ensaios teóricos e estudos bibliométricos e sociométricos com abordagem descritiva dos resultados. A seguir serão exploradas cada uma das linhas de pesquisa supracitada, para apresentar os avanços nas investigações que se utilizam da Teoria Institucional.

\subsection{ANÁLISE DAS LINHAS DE PESQUISAS}

\subsubsection{Influência das forças macro institucionais}

Com o surgimento e expansão da adoção dos padrões e normas internacionais de Contabilidade, alguns estudiosos dedicaram-se a estudar as razões pelas quais as International Financial Reporting Standards (IFRS) foram adotadas voluntariamente (ver por exemplo GUERREIRO; RODRIGUES; CRAIG, 2012; MAROUN; VAN ZIJL, 2016). Neste novo direcionamento de pesquisa, busca-se explicar como as pressões institucionais influenciam a adoção voluntária da IFRS e explicar os fatores que contribuíram para a adoção antecipada a nível nacional do IFRS antes da ampla adoção global. Ainda neste sentido, outras forças macro institucionais foram objeto de estudo para elucidar os fatores que influenciam e modificam os sistemas de Contabilidade. Dentre elas, destaca-se o papel da pressão isomórfica coercitiva de entidades internacionais sobre os sistemas de Contabilidade locais (HASSAN; RANKIN; LU, 2014).

Em relação às forças e pressões externas sobre a configuração das práticas, Griffith, Hammersley e Kadous (2015) apresentaram as forças institucionais que moldaram as práticas de auditoria no que tange a mensuração, valoração e acuracidade das transações. Como pressões institucionais foram apresentadas por exemplo, o aumento na complexidade - nas últimas duas décadas - das estimativas do valor de ativos e a falta de orientações sobre como os auditores devem. No que tange às práticas de alocação de capital, Jabbour e Abdel-Kader (2015) mostraram que as lógicas embutidas, em um novo sistema de avaliação de risco implementado, foram fortes e promoveu mudanças nas rotinas internas da organização. Estas pesquisas apresentam casos de como o isomorfismo coercitivo, normativo, mimético funcionam como direcionadores para o cumprimento das IFRS, ao mesmo tempo em que apresentam as lógicas para a resistência. (MAROUN; VAN ZIJL, 2016)

No setor público, alguns estudos dedicaram-se a estudar as forças e pressões externas (neste caso os padrões de Contabilidade internacionais aplicada ao setor público) que influenciaram a mudança na Contabilidade local. Essa mudança pode não ser sempre bem-sucedida por causa da resistência em função de como o processo de mudança foi conduzido. Isso se justifica, porque realidades locais diferentes respondem de formas heterogêneas. Em locais onde a tradição da Contabilidade pública já é bem consolidada ou forte, a adoção do padrão internacional sofre uma grande resistência, ao contrário de onde a Contabilidade pública ainda não o é (ALBU; ALBU; ALEXANDER, 2014; OULASVIRTA, 2014). 
A escolha pelo arcabouço do isomorfismo de DiMaggio e Powell (1983) parece ser a principal entre os autores quando se trata de pressões e forças externas que influenciam a Contabilidade. Não obstante, alguns estudos consideram que a organização não é passiva no ambiente organizacional. Ela responde às mudanças de forma estratégica, justificando assim a utilização do modelo de Oliver (1991).

Ao se mencionar desenvolvimento ou configurações de padrões, mais especificamente os relatórios da Contabilidade social e ambiental, alguns estudos nesta linha investigaram os motivos para a divulgação desses tipos de relatórios em diversos contextos, e as lógicas por trás da estruturação dos relatórios. As investigações de Bebbington, Higgins e Frame (2009) e Momin e Parker (2013) mostram que a decisão favorável à divulgação dos relatórios socioambientais não parece ser uma escolha racional, mas sim por razões de legitimidade, ou prossecução de uma estratégia de diferenciação. Assim, a busca pela legitimidade da organização contribui para o isomorfismo dos relatórios. Além dessa forma de isomorfismo, Oliveira et al. (2012) também destacam a influência dos agentes reguladores sobre a divulgação e configuração dos relatórios.

Assim, os artigos convergem na ideia de que quando as organizações se deparam com incertezas e ameaças à continuidade, tendem a copiar estruturas e modelos adotados por outras organizações percebidas como eficientes e racionais (DIAS-FILHO; MOURA, 2013; GRECCO et al., 2013). O que põe em destaque a influência de forças socioculturais sobre a Contabilidade na busca pela legitimação das empresas.

Neste sentido, o isopraxismo e o isomorfismo oferecem poder explicativo para análise das diferenças e semelhanças em relatórios, pois, permite aos pesquisadores obter uma melhor compreensão de quando e como as ideias transladadas podem levar à homogeneidade ou heterogeneidade da prática ou do campo institucional (ADAMS et al., 2016). Desta forma, é esclarecido que as lógicas da configuração dos relatórios socioambientais podem ser conflitantes, e podem acarretar uma mudança na visão dos agentes ou atores (EDGLEY; JONES; ATKINS, 2015).

No cerne da Contabilidade Gerencial, estudos se concentraram no processo de institucionalização de práticas orçamentárias (KREUZBERG; BECK; LAVARDA, 2016), práticas de custos (CALLADO; PINHO, 2015), e no processo de desinstitucionalização que agem sobre os artefatos (REZENDE; GUERREIRO; DALMÁCIO, 2012).

Estes estudos ampliam a visão que encontraram Moll, Burns e Major (2006) nesta linha. Além da configuração de padrões financeiros, os pesquisadores estão se dedicando a aplicação e desenvolvimento de padrões ou configurações de relatórios socioambientais e Relatos Integrados. Outras investigações utilizaram a Teoria Institucional aplicadas em áreas distintas como Auditoria (DEDOULIS, 2016); Mercado de Capitais (ABRAHAM; SHRIVES, 2014); e Transparência (PALERMO, 2014).

\subsubsection{Estruturação do campo organizacional}

Entender as tensões e contradições que motivam a mudança e o jogo de poder e força dos atores institucionais permite uma análise da estruturação do campo organizacional e como o processo de institucionalização é conduzido. Nas investigações sobre 
institucionalização, alguns pesquisadores dedicaram-se a estudar as forças que influenciam neste processo (LAVARDA; FELIU; PALANCA, 2009), a estruturação das normas, hábitos e rotinas de Contabilidade e relatórios sociais e ambientais (CONTRAFATTO; BURNS, 2013), para elucidar que fatores externos estão continuamente relacionados com a esfera intra-organizacional e tem o poder de moldar até as ações dos agentes mais influentes, e que as regras e rotinas emergentes da Contabilidade são influenciadas e implicadas na mudança organizacional e vice-versa. Em outras palavras, independentemente dos aspectos conceituais técnicos, a mudança tem grande probabilidade de ser institucionalizada se estiver de acordo com a lógica institucional presente no campo institucional vigente na empresa (ROCHA; GUERREIRO, 2010).

Destarte, os Relatórios Sociais e Ambientais (RSA) surgem no contexto da emergente lógica de sustentabilidade, em que o grau de desenvolvimento da insensibilidade simbólica e material à lógica da maximização de lucro prevalecente, determina o formato da prática do RSA, mais especificamente, a presença de resistência simbólica ou material à lógica de sustentabilidade pode explicar a ausência completa de RSA (BOUTEN; EVERAERT, 2015).

Neste sentido, atenção vem sendo dada as confrontações das lógicas institucionais (HYVÖNEN et al., 2009) para aclarar que a mudança depende, também, da aceitação das lógicas advindas de diferentes pressões externas, ou situações de dentro da organização (CARLSSON-WALL; KRAUS; MESSNER, 2016), assim a compatibilidade das lógicas pode variar não apenas entre campos e organizações, como a literatura enfatiza, mas também entre situações dentro de uma organização. Além disso, o conflito entre as lógicas em um campo é mediado pelas homologias entre as lógicas de dentro e de fora do campo que impulsionam novas lógicas no mesmo, como demonstra o trabalho de Ezzamel, Robson e Stapleton (2012).

Contudo, a dinâmica por meio da qual as práticas socioambientais passam a ser institucionalizadas é um processo multi-passo recursivo e progressivo, em particular, no qual três processos principais e resultados relacionados foram identificados: a construção do sistema de significado comum em torno da ideia de responsabilidade social e ambiental; practicalisation, pelo qual regras e rotinas foram adotadas e difundidas dentro da organização; e o reforço por meio da adoção de estruturas e processos gerenciais intra-organizacionais. Por meio deste processo é possível investigar, como realizado por Contrafatto (2014), de que forma a lógica da Contabilidade (social e ambiental) é construída e posta em prática, e como estas práticas são reforçadas na organização.

Por sua vez, o trabalho institucional dá destaque ao papel dos atores na condução do processo de mudança. Assim, o trabalho institucional, incluindo teorização, apelos retóricos, construção de redes normativas e educação, confere a um grupo estabilidade e influência, possibilitando-o acessar as categorias convencionais da difusão - interrupção, criação e manutenção (HAYNE; FREE, 2014). Contudo, a interação entre os atores nacionais e transnacionais tornam um mecanismo de mudança aceitável, mas quando as novas regras são anexadas às existentes, elas as desestabilizam e também podem diminuir o impulso para mudanças mais amplas (ALON; DWYER, 2016).

A linha de investigação relacionada ao uso de informações contábeis nos trabalhos analisados dedicam-se a estudar a gestão e avaliação de desempenho (ARTZ; HOMBURG; 
RAJAB, 2012), o uso das informações da Contabilidade na gestão pública (JOHANSSON; SIVERBO, 2009) e o (de)coupling da utilização das informações de certas práticas (HENTTU-AHO; JÄRVINEN, 2013). O uso da informação pode ser heterogêneo entre as organizações em virtude da complexidade institucional enfrentadas (AMANS; MAZARS-CHAPELON; VILLESĖQUE-DUBUS, 2015). Desta forma, a complexidade institucional pode ser vista como um recurso, e não como uma restrição, que oferece oportunidades à gestão (BRIVOT; $\mathrm{CHO}$; KHUN, 2015).

\subsubsection{Legitimidade e organizações}

Nesta linha de investigação, outras pesquisas exploraram a decisão para a divulgação dos relatórios, adoção de práticas, normas, hábitos e rotinas, não por uma escolha racional, mas sim por razões de legitimidade, ou prossecução de uma estratégia de diferenciação, ou para dar a impressão de modernidade, ou ainda avaliar mudanças devido a deslegitimação e busca pela reconquista da legitimidade.

As pressões socioculturais (LIMA et al., 2015) e ambientais (BEDDEWELA; HERZIG, 2013), que fazem com que as empresas se configurem de uma maneira única no que tange as demonstrações sociais corporativas, são associadas de acordo com Beddewela e Herzig (2013) às pressões isomórficas e razões de legitimidade.

A legitimidade também pode ser utilizada como artifício de comunicação de uma imagem percebida a nível mais amplo, conforme demonstra o estudo de Antipova e Bourmistrov (2013). Como exemplo, a adoção do padrão internacional do setor público pela Rússia contemporânea buscou a "modernização" alinhando as tensões entre as ideias globais contidas nas normas internacionais e sua materialização nas práticas locais. Contudo, as ideias globais entram em conflito com as tradições existentes na Contabilidade pública russa.

A Teoria Institucional mostra que existe uma lacuna cultural e geográfica entre as subsidiárias e a controladora. As controladas tendem a aderir aos mecanismos isomórficos do ambiente local como a política, cultura e negócios. Por isso as subsidiárias têm vários motivos para apresentar as informações sociais e ambientais para conquistar a legitimidade interna e externa. (MOMIN; PARKER, 2013)

A legitimidade é tida como um elemento crucial para o campo institucional. Neste sentido, a perda de legitimidade e a busca pela relegitimação podem ser alcançadas por meio de estratégias discursivas (WHITTLE; CARTER; MUELLER, 2014). A (perda da) legitimidade também vem sido evocada para explicar processos de mudança na organização (KACHELMEIER; RASMUSSEN; SCHMIDT, 2016).

\subsubsection{Agência e poder na análise institucional}

Uma das principais críticas sofridas pela Teoria Institucional é a pouca ênfase dada às ações e aos interesses dos atores sociais (LEONEL-JUNIOR; CUNHA, 2012). Neste sentido, novas investigações nesta linha dedicaram-se a investigar as escolhas da organização; negociações entre partes; Contabilidade em governos locais; e poder e política e 
sua influência. As escolhas da organização podem ser mediadas pelas relações de poder e agência (UGRIN, 2009) além de pressão isomórficas para adequar os sistemas contábeis que não são utilizados devido a cultura predominante. Isto pode influenciar a relação entre a formulação de estratégias e o sistema de controle gerencial (TUCKER; PARKER, 2013).

Alguns estudos dedicaram-se a analisar as relações e negociações entre atores dentro da mesma organização ou em organizações diferentes. Os temas dos artigos analisados estudaram a relação entre auditores internos e administração (CHRISTOPHER; SARENS; LEUNG, 2009), e negociação de compensações de gestores (HERMANSON et al., 2012). Alguns autores aplicaram esta análise no setor público ao estudar a relação entre os auditores do estado e os auditados (FUNNELL; WADE, 2012). Nesta linha mostra-se que os estudos tendem a confrontar teorias (ver por exemplo: CHRISTOPHER; SARENS; LEUNG, 2009, HERMANSON et al., 2012) mostrando que a abordagem individual de cada uma não é suficiente para explicar os processos.

Ao se estudar a estruturação do campo organizacional, alguns autores focam seus estudos nas relações sociopolíticas e assimetrias de forças ou poder existente nelas, tanto no contexto intraorganizacional, quanto no interorganizacional (CHANG, 2009; HOOKS; STEWART, 2015). Neste contexto, a mudança promovida pelo processo de regulação do mercado seguindo as mudanças coercivas remete a práticas de Contabilidade cooptadas para fornecer legitimidade, resistência, e para redistribuir riqueza e poder na sociedade.

Por outro lado, a nível micro institucional, as práticas da gestão de desempenho estão implicadas no exercício do poder, com especial referência para a capacidade individual dos gerentes balancear ou equilibrar concepções de desempenho entre mais ou menos institucionalizados, enquanto prossegue a mudança organizacional (YANG; MODELL, 2012); e na decisão política de adotar objetivos sub ótimos. (DA COSTA; LOPES, 2012)

Alguns estudos enfatizaram a análise das considerações sobre a mudança de domínio, dando atenção para sobre como a experiência profissional é ampliada para novas áreas de atuação (SUDDABY; SAXTON; GUNZ, 2015) e também consideram a influência dos agentes na reconfiguração do seu ambiente institucional (MULLIGAN; OATS, 2016).

\subsubsection{Contabilidade e busca por eficiência}

Apesar desta linha estar focada na literatura econômica, as investigações recentes mostram uma abordagem alternativa a esta corrente. Alguns estudiosos, por exemplo, buscaram aplicar o arcabouço da institucional com foco na eficiência para analisar a precificação pela Teoria Institucional econômica. Contudo a OIE não se mostrou suficiente para identificar os possíveis modelos ótimos (MATTIMOE; SEAL, 2011). Outros estudos buscaram identificar mudanças em busca de eficiência (ver por exemplo: QIAN; BURRITT; MONROE, 2011; EGAN, 2014).

Na busca por eficiência, alguns pesquisadores se dedicaram a analisar o processo de padronização de práticas e sistemas. Por vezes, a padronização parte de imposições para adoção de novos sistemas, o que pode ser resultado de uma mudança na estrutura de propriedade de uma organização. 
Desta forma, quando há uma imposição de novos sistemas de avaliação de desempenho o agente institucional ganha um papel de destaque na estruturação das práticas organizacionais e institucionais (CONRAD; USLU, 2012), uma vez que a mudança pode influenciar na elasticidade e no comportamento dos custos (HOLZHACKER; KRISHNAN; MAHLENDORF, 2015) da entidade. Além disso, os valores e regras difundidos de um contexto global (o que impõe a mudança) para um contexto local por meio dos sistemas formais, podem conflitar com a realidade local fazendo com que os resultados esperados não sejam atingidos (BOITIER; RIVIÈRI, 2013).

$\mathrm{Na}$ literatura brasileira, Liszbinski et al. (2014) analisaram a conformidade de um grupo de empresas brasileiras às normas exigidas para o reconhecimento contábil de ativos intangíveis, à luz da Teoria Institucional para evidenciar que as instituições, mais facilmente compreendidas pelas regras impostas a um determinado ambiente, determinam o comportamento e a ordenação tanto das relações entre os indivíduos como entre as organizações.

\section{DISCUSSÃO E DIRECIONAMENTOS PARA FUTURAS INVESTIGAÇÕES}

Em relação às linhas de pesquisa pode-se constatar que a influência das formas macro institucionais, os trabalhos concentraram-se em explicar e identificar as forças que influienciam os sistemas contábeis das organizações, alguns dedicaram-se a estudar os padrões de Contabilidade internacional no setor privado (GUERREIRO; RODRIGUES; CRAIG, 2012) e público (ALBU; ALBU; ALEXANDER, 2014, OULASVIRTA, 2014). Outros dedicaram-se a estudar as configurações de práticas e evidenciações dos relatórios socioambientais (BEBBINGTON; HIGGINS; FRAME, 2009) e a inter-relação entre tais relatórios com a Contabilidade Gerencial (CONTRAFATTO; BURNS, 2013). Contudo, a complexidade dessas interações resultantes da aprendizagem, interações políticas e conflitos de valores, levam a resultados ainda incertos.

Em comparação com o trabalho de Moll, Burns e Major (2006) nota-se que as pesquisas não estão sendo direcionadas para estudar configuração dos padrões financeiros, mas sim para novas aplicações na Contabilidade social e ambiental. No entanto, se as intervenções da Contabilidade Social e Ambiental realmente geram a mudança desejável é algo que exige mais pesquisa e investigação (CONTRAFATTO, 2014).

Com relação a estruturação do campo organizacional, alguns autores preocuparam-se em estudar a institucionalização de normas, hábitos, rotinas também em relação à Contabilidade social e ambiental (CONTRAFATTO, 2014). Estes estudos fornecem insights sugestivos para a compreensão de como e em que medida as intervenções podem influenciar o processo de construção e institucionalização da Responsabilidade Social e Ambiental em vários contextos. Outros dedicaram-se a estudar a utilização das informações no setor público (JOHANSSON; SIVERBO, 2009) e privado (ARTZ, HOMBURG; RAJAB, 2012) e (de)coupling. Alguns autores estudaram a evolução dos sistemas, focados na mudança nos ambientes organizacionais (HYVÖNEN et al., 2012). Nesta perspectiva, os estudos trabaIham sobre mudança e utilizam alguns arcabouços como Lógica Institucional (HYVÖNEN et al., 2009, GUERREIRO; RODRIGUES; CRAIG, 2012) e Contradições Institucionais (CRUZ; MAJOR; SCAPENS, 2009). Outro arcabouço que está sendo utilizado, principalmente no setor público, é o empreendedorismo institucional. 
Tais conceitos, com exceção da contradição institucional, não estavam presentes na revisão de Moll, Burns e Major (2006), e podem ser tendências na Análise Institucional. Além disso, a noção de trabalho institucional ou empreendedorismo institucional oferece uma lente para examinar a difusão de inovações na pesquisa contábil (HEYNES; FREE, 2014).

No entanto, ainda são necessárias mais pesquisas sobre a natureza das rotinas e seus processos de reprodução. Apesar do esforço da literatura em entender as rotinas como disposições e como comportamentos recorrentes (VAN DER STEEN, 2011), não está claro como esses diferentes conceitos estão relacionados. Assim emergem alguns questionamentos: as rotinas da Contabilidade Gerencial evoluem de um conjunto de comportamentos recorrentes, para um conjunto de disposições? Como as instituições direcionam o processo de reprodução das rotinas? Qual a relação entre o aspecto ostensivo das rotinas e as disposições que fazem parte dessas rotinas?

Novas investigações podem direcionar esforços na compreensão de micro processos pelos quais as rotinas evoluem e como elas são reproduzidas. Isto pode contribuir para aprimorar a compreensão dos processos de mudança em Contabilidade, pois, as rotinas são um aspecto importante, mas ainda um pouco negligenciado, desses processos de mudança (VAN DER STEEN, 2011). Ainda neste sentido, outra dimensão negligenciada da Teoria Institucional são as "rotinas-como-tréguas" (RICHARDSON; KILFOYLE, 2016). Esta abordagem fornece uma alternativa à "nova" visão da Teoria Institucional do poder e do conflito que leva ao isomorfismo (captura) ou ao decoupling (conformidade simbólica) e à "antiga" Teoria Institucional que se concentra na mudança contábil como a institucionalização de aprendizado organizacional.

Além disso, a literatura ainda é vaga sobre o resultado das interações entre lógicas institucionais e os ajustamentos necessários - na prática ou inovação, ou na organização - no processo de mudança. Assim, pode haver pouca ou nenhuma modificação na prática ou organização; ou, a organização altera a estrutura do artefato ajustando-o a estrutura da organização; ou, a organização altera a sua estrutura para se adaptar ao artefato; ou a organização altera tanto sua estrutura quanto a do artefato. 0 que define esse ajustamento, em termos de similaridade e extensão da prática e sua relação com as lógicas institucionais, ainda é um ponto a ser esclarecido.

A linha de legitimidade e organização buscou as razões e mecanismo para a legitimação. (MASRANI; MCKIERNAN, 2011; BEDDEWELA; HERZIG, 2013). Da mesma forma que constatado por Moll, Burns e Major (2006), as utilizações se dão de forma semelhante, incluindo na perspectiva de reformas para firmar a imagem de "moderno" como pode ser observado no estudo de Antipova e Bourmistrov (2013). Porém, os estudos não se concentraram em entender como as organizações conquistam a legitimidade, tampouco a relegitimidade em situações de deslegitimação. Neste sentido, novas pesquisas podem buscar entender os discursos empregados pelas organizações para conferir legitimidade e aceitação de suas ações.

Na linha do papel da agência e análise institucional, alguns autores dedicaram estudar as escolhas da organização como Ugrin (2009) e Tucker e Parker (2013). Outros estudaram as negociações entre partes em relação a compensação dos gestores (HERMANSON et al., 2012) e negociações entre auditores e auditados (FUNNELL; WADE, 2012). 
Alguns autores focaram nas relações sociopolíticas e assimetrias de forças e poder (CHANG, 2009; YANG; MODELL, 2012). Estas pesquisas, avançam nos diferentes contextos analisados em relação aos estudos previamente apresentados por Moll, Burns e Major (2006). No entanto, pesquisas futuras podem ajudar a definir melhor o contexto político-econômico dentro do qual as organizações operam. Neste sentido, um esforço deve ser realizado para examinar as formas em que a cultura e a retórica contábeis estão envolvidas para alcançar agendas sociais, políticas e econômicas. Neste sentido, pesquisas mais aprofundadas poderiam examinar como as organizações procuram gerenciar efetivamente seu ambiente político e as estratégias empregadas.

Por fim, alguns estudos utilizaram o arcabouço da institucional com foco na eficiência. Contudo, é de se ressaltar que ao invés da procura por eficiência como era visto nos artigos analisados por Moll, Burns e Major (2006), estes agora utilizam outras vertentes da teoria. Antes nesta perspectiva, a busca pela configuração ótima era estudada pela NIE, já os artigos analisados visam estudar eficiência, mas utilizando outros construtos teóricos como pode ser visto em Mattimoe e Seal (2011), Qian, Burritt e Monroe (2011). Nestes artigos, a busca por eficiência não está relacionada à configuração do padrão da Contabilidade, mas sim ao todo da organização, seja ao determinar preço com influência da Contabilidade e marketing, seja na gestão de resíduos. A configuração da Contabilidade não está em jogo nas análises feitas nestes artigos, mas a melhoria na eficiência tem dependência com as informações produzidas pela Contabilidade.

Ao analisar os artigos, observa-se um destaque que vem sendo dado ao contexto da Contabilidade no setor público e da Contabilidade social e ambiental. Naturalmente, o cenário do setor privado, onde se estudam indústrias e empresas prestadoras serviços, continua com ampla aplicação. Mas o crescimento na aplicação em outros âmbitos, mostra uma tendência dos autores, principalmente internacionais, em estudar contextos diversos e desafiadores em função de sua complexidade. Os pesquisadores no Brasil ainda continuam focados de modo clássico na aplicação da Teoria Institucional no setor privado, especificamente em Contabilidade Gerencial e Controladoria, com poucas exceções. $\mathrm{O}$ que mostra que alguns pesquisadores nacionais estão atentos a seguir um percurso de análise institucional similar ao da pesquisa internacional.

As pesquisas brasileiras estão mais focadas em analisar a influência das forças macro institucionais e a estruturação do campo organizacional. Na primeira linha de pesquisa o principal foco da investigação brasileira é o processo de institucionalizção clássico, com grande utilização do arcabouço do isomorfismo, (por exemplo: DIAS-FILHO; MOURA, 2013; GRECCO et al., 2013). Em paralelo, também, as pressões que contribuem para o processo de desistitucionalização no Brasil (REZENDE; GUERREIRO; DALMÁCIO, 2012) tais como diminuição dos índices de inflação da economia brasileira; mudança das leis sobre publicação de informação contábil corrigida; não exigência deste tipo de informação pelo mercado financeiro; custos de manutenção da prática superam os benefícios da informação gerada; surgimento de novas tecnologias contábeis; níveis de inflação no período (mês e ano); e harmonização internacional das práticas contábeis. A outra linha de investigação, que trata sobre a estruturação do campo organizacional, possui um foco na mudança de sistemas como de Contabilidade Gerencial, custos e controle de gestão (LAVARDA; FELIU; PALANCA, 2009; ROCHA; GUERREIRO, 2010). 
Por fim, a comparação dos artigos nacionais e internacionais analisados em relação às linhas de pesquisa de Moll, Burns e Major (2006) permite identificar que as linhas de pesquisa relacionadas com a influência das forças macro institucionais nos sistemas contábeis das organizações e a estruturação do campo organizacional são as linhas onde houveram mais pesquisas, tanto a nível internacional quanto nacional. Contudo, a linha que trata sobre legitimidade e organizações seguiu sendo uma linha pouco explorada, com poucos artigos tanto nacional quanto internacional. 0 papel da agência na análise institucional foi mais expressivo na pesquisa internacional do que na pesquisa nacional, e Contabilidade como configuração eficiente apresentou poucos artigos, em ambas pesquisas, ressaltando-se que esta linha os artigos buscam estudar a eficiência com teorias que não são a NIE.

\section{CONCLUSÃO}

As seções anteriores permitem observar que as investigações que se valem da Teoria Institucional como plataforma teórica estão direcionadas a estudar assuntos variados na área contábil, tais como: a Contabilidade Gerencial e Financeira, Auditoria e Relatórios Socioambientais em contextos variados dentre os três setores. A revisão dos artigos permite observar que a Teoria Institucional é comumente empregada em Contabilidade Gerencial, contudo alguns pesquisadores têm dado atenção para outros segmentos com ambientes institucionais mais complexos.

Os modelos teóricos desenvolvidos no arcabouço da Teoria Institucional são bastante utilizados para explicar a modelagem dos sistemas de Contabilidade. Contudo não foi identificado um modelo que pudesse explicar como os sistemas contábeis irão variar de acordo com a pressão institucional (ou as pressões institucionais) que estão inter-relacionadas ao campo organizacional.

De modo geral, os artigos analisados neste estudo mostram a ampliação do escopo da Teoria Institucional com o arcabouço do institucionalismo histórico, lógicas e empreendedores institucionais, antes não contemplados pela revisão realizada por Moll, Burns e Major (2006). É possível identificar diversas forças que modificam e moldam o ambiente institucional. Outra contribuição está na forma como os mecanismos intra e interinstitucionais são usados para moldar o ambiente organizacional, mostrando as repostas estratégicas da organização. Outros estudos concentraram-se em como foi o processo de institucionalização e modelagem de relatórios socioambientais.

Do ponto de vista metodológico a maioria das pesquisas realizaram estudos de caso. Contudo alguns selecionaram variáveis da Teoria Institucional e realizaram estudos quantitativos. A seleção da metodologia de estudo de caso permanece predominante pelos pressupostos utilizados pelas pesquisas, servindo para analisar a inter-relação entre os atores, práticas e hábitos, o processo de como a Contabilidade em contexto local é modificada ou como a Contabilidade Gerencial é moldada. Uma linha importante é mostrada como a abordagem alternativa trata as questões de eficiência, não se baseando na literatura clássica da economia.

Futuras investigações podem explorar a relação existente entre os modelos desenvolvidos no arcabouço da Teoria Institucional, considerando a complexidade dos contextos. 
Esta interação, pode surgir como um modelo de análise integrado e sistêmico, que possibilite a complexidade da análise institucional. Outras oportunidades teóricas podem ser apontadas para uma análise da evolução institucional ao longo do tempo para fornecer uma melhor compreensão da forma como o campo organizacional e institucional são moldados.

Algumas limitações da revisão podem ser apontadas. Primeiramente, a forma de seleção dos artigos, internacionais e com a limitação pela qualidade da revista, pode ter deixado artigos significativos em periódicos de estrato menos elevado. Segundo, a classificação na linha de pesquisa, pode conter viés dos pesquisadores e pode não ser o mesmo que 0 pretendido pelos autores. Porém foram realizados com base na contribuição das obras para a teoria, de acordo com nossa visão.

Apesar dos esforços para analisar os artigos, futuras revisões podem se dedicar a estudar a aplicação da Teoria Institucional em cada subárea da Contabilidade - ou para cada linha de investigação - para ter achados mais específicos e aprofundados em cada uma delas. Além disso, em termos metodológicos, recomenda-se a utilização de outras abordagens de identificação dos artigos com base na técnica de snowball, ou identificação dos artigos (ou artigos mais citados) em plataformas de base de dados - a exemplo Scopus, Science Direct ou Google Acadêmico.

Por fim, acreditamos que nosso estudo proporcionou uma análise sistemática e informativa da literatura contábil baseada na Teoria Institucional que pode expandir o entendimento, o debate e o uso da Teoria Institucional como lente teórica para a explicação de fenômenos complexos na área de Contabilidade. Além disso, nosso estudo teve como um dos seus intuitos mapear a pesquisa institucional em Contabilidade com a finalidade de ajudar pesquisadores menos experientes no entendimento da Teoria Institucional, e como essa teoria pode ser utilizada em diferentes linhas de pesquisas. De forma geral, nossa esperança é que discutindo as futuras direções de pesquisas e analisando de forma sistemática a pesquisa institucional em Contabilidade, essa nossa revisão da Teoria Institucional encoraje outros pesquisadores a considerarem essa teoria como uma potente forma de explicar e entender fenômenos relevantes para o desenvolvimento da Contabilidade.

\section{REFERÊNCIAS}

ABERNETHY, M.; CHUA, W.F. A field study of control system redesign: the impact of institutional process on strategic choice. Contemporary Accounting Research, v. 13, 1996.

ABRAHAM, S.; SHRIVES, P.J. Improving the relevance of risk factor disclosure in corporate annual reports. The British Accounting Review, v. 46, n. 1, p. 91-107, 2014.

ADAMS, C.A. et al. Exploring the implications of integrated reporting for social investment (disclosures). The British Accounting Review, v. 48, n. 3, p. 283-296, 2016.

ALBU, C.N.; ALBU, N.; ALEXANDER, D. When global accounting standards meet the local context-Insights from an emerging economy. Critical Perspectives on Accounting, v. 25, n. 6, p. 489-510, 2014.

ALLEYNE, P.; HUDAIB, M.; PIKE, R. Towards a conceptual model of whistle-blowing intentions among external auditors. The British Accounting Review, v. 45, n. 1, p. 10-23, 2013. 
ALON, A.; DWYER, P.D. Early Adoption of IFRS as a Strategic Response to Transnational and Local Influences. The International Journal of Accounting, v. 49, n. 3, p. 348-370, 2014.

ALON, A.; DWYER, P.D. SEC's acceptance of IFRS-based financial reporting: An examination based in institutional theory. Accounting, Organizations and Society, v. 48, p. 1-16, 2016.

AMANS, P.; MAZARS-CHAPELON, A.; VILLESÈQUE-DUBUS, F. Budgeting in institutional complexity: The case of performing arts organizations. Management Accounting Research, v. 27, p. 47-66, 2015.

ANSARI, S.; EUSKE, K.J. Rational, rationalizing and reifying uses of accounting data in organizations. Accounting, Organizations and Society, v. 12, n. 6, 1987.

ANTIPOVA, T.; BOURMISTROV, A. Is Russian Public Sector Accounting in the process of modernization? An Analysis of Accounting Reforms in Russia. Financial Accountability \& Management, v. 29, n. 4, 2013.

ARTZ, M.; HOMBURG, C.; RAJAB, T. Performance-measurement system design and functional strategic decision influence: The role of performance-measure properties. Accounting, Organizations and Society, v. 37, n. 7, p. 445-460, 2012.

BAXTER, J.; CHUA, W.F. Alternative Management Accounting Research - Whence and whither. Accounting, Organizations and Society, v. 28, n. 2, 2003.

BEBBINGTON, J.; HIGGINS, C.; FRAME, B. Initiating sustainable development reporting: evidence from New Zealand. Accounting, Auditing \& Accountability Journal, v. 22, n. 4, p. 588-625, 2009.

BEDDEWELA, E.; HERZIG, C. Corporate social reporting by MNCs' subsidiaries in Sri Lanka. Accounting Forum, v. 37, n. 2, p. 135-149, 2013.

BOITIER, M.; RIVIÈRE, A. Freedom and responsibility for French universities: from global steering to local management. Accounting, Auditing \& Accountability Journal, v. 26, n. 4, p. 616-649, 2013.

BOUTEN, L.; EVERAERT, P. Social and environmental reporting in Belgium: 'Pour vivre heureux, vivons cachés'. Critical Perspectives on Accounting, v. 33, p. 24-43, 2015.

BRIVOT, M.; CHO, C.H.; KUHN, J.R. Marketing or parrhesia: A longitudinal study of AICPA's shifting languages in times of turbulence. Critical Perspectives on Accounting, v. 31, p. 23-43, 2015.

BURNS, J. The Dynamics of accounting change: inter-play between new practices, routines, institutional, power and politics. Accounting, Auditing and Accountability Journal, v. 13, n. 5, 2000.

BURNS, J.; SCAPENS, R.W. Conceptualizing management accounting change: an institutional framework. Management Accounting Research, v. 11, 2000.

CALLADO, A.A.C.; PINHO, M.A.B. Evidências de isomorfismo mimético sobre práticas de gestão de custos entre micro e pequenas enpresas de diferentes setores de atividade. Contabilidade Vista \& Revista, v. 25, n. 2, 2015. 
CARLSSON-WALL, M.; KRAUS, K.; MESSNER, M. Performance measurement systems and the enactment of different institutional logics: Insights from a football organization. Management Accounting Research, v. 32, p. 45-61, 2016.

CARPENTER, V.L.; DIRSMITH, M. Sampling and the abstraction of knowledge in the auditing profession: an extend institutional theory perspective. Accounting, Organization and Society, v. 18, 1993.

CHANG, L.-C. The impact of political interests upon the formulation of performance measurements: the nhs star rating system. Financial Accountability \& Management, v. 25, n. 2, 2009.

CHENHALL, R. H.; SMITH, D. A review of Management Accounting Research: 1980-2009. Accounting and Finance, v. 51, n. 1, 2011.

CHRISTOPHER, J.; SARENS, G.; LEUNG, P. A critical analysis of the independence of the internal audit function: evidence from Australia. Accounting, Auditing \& Accountability Journal, v. 22, n. 2, 2009.

COLBERT, G.; SPICER, B. A multi-case investigation of a theory of the transfer pricing process. Accounting, Organizations and Society, v. 17, n. 1, 1995.

CONRAD, L.; USLU, P.G. UK health sector performance management: Conflict, crisis and unintended consequences. Accounting Forum, v. 36, n. 4, p. 231-250, 2012.

CONTRAFATTO, M. The institutionalization of social and environmental reporting: An Italian narrative. Accounting, Organizations and Society, v. 39, n. 6, p. 414-432, 2014.

CONTRAFATTO, M.; BURNS, J. Social and environmental accounting, organisational change and management accounting: A processual view. Management Accounting Research, v. 24, n. 4, p. 349-365, 2013.

COOPER, S.; PARKES, C.; BLEWITT, J. Can accreditation help a leopard change its spots? Accounting, Auditing \& Accountability Journal, v. 27, n. 2, p. 234-258, 2014.

CRUZ, I.; MAJOR, M.; SCAPENS, R. W. Institutionalization and practice variation in the management control of a global/local setting. Accounting, Auditing \& Accountability Journal, v. 22, n. 1, p. 91-117, 2009.

DA COSTA, A.R.; LOPES, F.D. Inserção de fornecedores locais como fonte de performance em custos de transação e legitimidade. BASE - Revista de Administração e Contabilidade da Unisinos, v. 9, n. 3, 2012.

DEDOULIS, E. Institutional formations and the Anglo-Americanization of local auditing practices: The case of Greece. Accounting Forum, v. 40, n. 1, p. 29-44, 2016.

DIAS-FILHO, J.M.; MOURA, F.V.D. Social Disclosures in Six Brazilian Banks - an Analysis in the Light of Institutional Theory. Revista Universo Contábil, v. 9, n. 3, p. 6-21, 2013.

DIMAGGIO, P.J.; POWELL, W.A. The iron cage revisited: institutional isomorphism and collective rationality in organizational fileld. American Sociological Review, v. 48, p. 147-160, 1983. 
EDGLEY, C.; JONES, M.J.; ATKINS, J. The adoption of the materiality concept in social and environmental reporting assurance: A field study approach. The British Accounting Review, v. 47 , n. 1, p. 1-18, 2015.

EGAN, M. Progress towards institutionalising field-wide water efficiency change. Accounting, Auditing \& Accountability Journal, v. 27, n. 5, p. 809-833, 2014.

EZZAMEL, M.; ROBSON, K.; STAPLETON, P. The logics of budgeting: Theorization and practice variation in the educational field. Accounting, Organizations and Society, v. 37, n. 5, p. 281-303, 2012.

FUNNELL, W.; WADE, M. Negotiating the credibility of performance auditing. Critical Perspectives on Accounting, v. 23, n. 6, p. 434-450, 2012.

GRECCO, M. C. P. et al. The voluntary disclosure of sustainable information: a comparative analysis of spanish and brazilian companies. Revista de Contabilidade e Organizações, v. 17, 2013.

GRIFFITH, E.E.; HAMMERSLEY, J.S.; KADOUS, K. Audits of Complex Estimates as Verification of Management Numbers: How Institutional Pressures Shape Practice. Contemporary Accounting Research, v. 32, n. 3, p. 833-863, 2015.

GUERREIRO, M.S.; RODRIGUES, L.L.; CRAIG, R. Voluntary adoption of International Financial Reporting Standards by large unlisted companies in Portugal - Institutional logics and strategic responses. Accounting, Organizations and Society, v. 37, n. 7, p. 482-499, 2012.

HASSAN, E.A.; RANKIN, M.; LU, W. The Development of Accounting Regulation in Iraq and the IFRS Adoption Decision: An Institutional Perspective. The International Journal of Accounting, v. 49, n. 3, p. 371-390, 2014.

HAYNE, C.; FREE, C. Hybridized professional groups and institutional work: COSO and the rise of enterprise risk management. Accounting, Organizations and Society, v. 39, p. 309-330, 2014.

HENTTU-AHO, T.; JÄRVINEN, J. A Field Study of the Emerging Practice of Beyond Budgeting in Industrial Companies: An Institutional Perspective. European Accounting Review, v. 22, n. 4, p. 765-785, 2013.

HERMANSON, D.R. et al. The Compensation Committee Process. Contemporary Accounting Research, v. 29, n. 3, p. 666-709, 2012.

HESFORD, J. W. et al. Management accounting: a bibliographic study. In: CHAPMAN, C.S.; HOPWOOD, A.G.; SHIELDS, M.D. (eds.). Handbooks of Management Accounting Research, v. 1, 2006.

HOLZHACKER, M.; KRISHNAN, R.; MAHLENDORF, M.D. The Impact of Changes in Regulation on Cost Behavior. Contemporary Accounting Research, v. 32, n. 2, p. 534-566, 2015.

HOOKS, J.; STEWART, R. The changing role of accounting: From consumers to shareholders. Critical Perspectives on Accounting, v. 29, p. 86-101, 2015.

HOQUE, Z. 20 years of studies on the balanced scorecard: trends, accomplishments, gaps and opportunities for future research. The British Accounting Review, v. 46, n. 1, 2014. 
HUSSAIN, M.; GUNASEKARAN, A. An Institutional perspective of non-financial management accounting measures: a review of the financial services industry. Managerial Auditing Journal, v. 17, 2002.

HUSSAIN, M.; HOQUE, Z. Understanding non-financial performance measurement practices in Japanese banks: a new institutional sociology perspective. Accounting, Auditing \& Accountability Journal, v. 15, n. 2, p. 162-183, 2002.

HYVÖNEN, T. et al. Institutional Logics, ICT and Stability of Management Accounting. European Accounting Review, v. 18, n. 2, p. 241-275, 2009.

HYVÖNEN, T.; JÄRVINEN, J.; OULASVIRTA, L.; PELLINEN, J. Contracting out municipal accounting: the role of institutional entrepreneurship. Accounting, Auditing \& Accountability Journal, v. 25, n. 6, p. 944-963, 2012.

JABBOUR, M.; ABDEL-KADER, M. Changes in capital allocation practices - ERM and organisational change. Accounting Forum, v. 39, n. 4, p. 295-311, 2015.

JOHANSSON, T.; SIVERBO, S. Explaining the utilization of relative performance evaluation in local government: a multi-theoretical study using data from sweden. Financial Accountability \& Management, v. 25, n. 2, 2009.

KACHELMEIER, S. J.; RASMUSSEN, S. J.; SCHMIDT, J.J. When Do Ineffective Audit Committee Members Experience Turnover? Contemporary Accounting Research, v. 33, n. 1, p. 228-260, 2016.

KREUZBERG, F.; BECK, F.; LAVARDA, C. E. F. Orçamento Base zero - um estudo de caso soba perspectiva da Teoria Institucional. Contabilidade Vista \& Revista, v. 27, n. 3, 2016.

LAVARDA, C.E.F.; FELIU, V.M.R.; PALANCA, M.B. Un análisis institucional de la implicación del proceso de cambio de los SCG en la evolución de la efi ciencia de las PYME. Revista Contabilidade \& Finanças, v. 20, n. 49, 2009.

LEONEL-JUNIOR, R.D.S.; CUNHA, C.R.D. Atores, trabalho institucional e a institucionalização da estratégia de diversificação em uma cooperativa agroindustrial. BASE - Revista de Administração e Contabilidade da Unisinos, v. 10, n. 1, 2012.

LIMA, L.C.D. et al. Práticas de governança corporativa adotadas e divulgadas pelos fundos de pensão brasileiros. Revista Contemporânea de Contabilidade, v. 12, n. 27, 2015.

LISZBINSKI, B.B. et al. Conformidade no reconhecimento de ativos intangíveis: um estudo na perspectiva da Teoria Institucional. Revista Contemporânea de Contabilidade, v. 11, n. 24, p. 85, 2014.

MAJOR, M.J.; RIBEIRO, J. A Teoria Institucional na Investigação em Contabilidade. In: MAJOR, M.J.; VIEIRA, R. (org.). Contabilidade e Controlo de Gestão: Teoria, Metodologia e Prática. Lisboa: Escolar Editora, 2009.

MAROUN, W.; VAN ZIJL, W. Isomorphism and resistance in implementing IFRS 10 and IFRS 12. The British Accounting Review, v. 48, n. 2, p. 220-239, 2016.

MASRANI, S.; MCKIERNAN, P. Accounting as a legitimising device in voluntary price agreements: The Dundee jute industry, 1945-1960. Critical Perspectives on Accounting, v. 22, n. 4, p. 415-433, 2011. 
MATTIMOE, R.; SEAL, W. Pricing in a Service Sector Context: Accounting and Marketing Logics in the Hotel Industry. European Accounting Review, v. 20, n. 2, p. 355-388, 2011. MEYER, J.W.; ROWAN, B. Institutionalized Organizations: Formal Structure as Myth and Ceremony. American Journal of Sociology, v. 83, n. $2,1977$.

MEZIAS, S.J.; SCARSELLETTA, M. Resolving financial reporting problems: An institutional analysis of the process. Administrative Science Quarterly, v. 39, n. 4, 1994.

MODELL, S. Strategy, political regulation and management control in the public sector: Institutional and critical perspectives. Management Accounting Research, v. 23, n. 4, p. 278-295, 2012.

MODELL, S. Institutional research on performance measurement and management in the public sector accounting literature: a review and assessment. Financial Accountability \& Management, v. 25, n. 3, p. 277-303, 2009.

MOLL, J.; BURNS, J.; MAJOR, M.J. Institutional Theory. In: HOQUE, Z. (ed.). Methodological Issues in Accounting Research: Theories, Methods and Issues. London: Spiramus, 2006.

MOMIN, M.A.; PARKER, L.D. Motivations for corporate social responsibility reporting by MNC subsidiaries in an emerging country: The case of Bangladesh. The British Accounting Review, v. 45, n. 3, p. 215-228, 2013.

MULLIGAN, E.; OATS, L. Tax professionals at work in Silicon Valley. Accounting, Organizations and Society, v. 52, p. 63-76, 2016.

OLIVEIRA, M. C. et al. Disclosure social de empresas brasileiras e britânicas à luz da teoria institucional. Advances in Scientific and Applied Accounting, v. 5, n. 1, 2012.

OLIVER, W. Expanding the scope of institutional analysis, In: POWELL, W.W.; DIMAGGIO, P.J. (org.). The new institutionalism in organizational analysis. Chicago: The Universiti Press, 1991.

OULASVIRTA, L. The reluctance of a developed country to choose International Public Sector Accounting Standards of the IFAC. A critical case study. Critical Perspectives on Accounting, v. 25, n. 3, p. 272-285, 2014.

PALERMO, T. Accountability and Expertise in Public Sector Risk Management: A Case Study. Financial Accountability \& Management, v. 30, n. 3, 2014.

PARKER, L.D.; NORTHCOTT, D. Qualitative generalising in accounting research: concepts and strategies. Accounting, Auditing \& Accountability Journal, v. 29, 2016.

QIAN, W.; BURRITT, R.; MONROE, G. Environmental management accounting in local government. Accounting, Auditing \& Accountability Journal, v. 24, n. 1, p. 93-128, 2011.

REZENDE, A. J.; GUERREIRO, R.; DALMÁCIO, F. Z. Uma análise do processo de desinstitucionalização de práticas contábeis de correção monetária em empresas brasileiras. Revista de Contabilidade \& Finanças - USP, São Paulo, v. 23, n. 58, 2012.

RICHARDSON, A.J.; KILFOYLE, E. Accounting institutions as truce: The emergence of accounting in the governance of transnational mail flows. Accounting, Organizations and Society, v. 55, p. 32-47, 2016. 
ROCHA, W.; GUERREIRO, R. Desenvolvimento De Modelo Conceitual De Sistemas De Custos - Um Enfoque Institucional. RCO - Revista de Contabilidade e Organizações, v. 4, n. 8, 2010.

RYAN, B.; SCAPENS, R.W.; THEOBALD, M. Research method and methodology in finance and accounting. London: Cengage Learning Emea, 2002.

SCAPENS, R.W. Understanding management accounting practices: A personal journey. British Accounting Review, v. 38, 2006.

SEO, M.G.; CREED, W.E.D. Institutional Contradictions, praxis and institutional change: a dialectical perspective. Academy of Management Review, v. 27, n. 2, 2002.

SHIELDS, M.D. Research in management accounting by North Americans in the 1990s. Journal of Management Accounting Research, v. 9, 1997.

SUDDABY, R.; SAXTON, G.D.; GUNZ, S. Twittering change: The institutional work of domain change in accounting expertise. Accounting, Organizations and Society, v. 45, p. 52-68, 2015.

TUCKER, B.P.; PARKER, L.D. Out of control? Strategy in the NFP sector: the implications for management control. Accounting, Auditing \& Accountability Journal, v. 26, n. 2, p. 234-266, 2013.

UGRIN, J.C. The Effect of System Characteristics, Stage of Adoption, and Experience on Institutional Explanations for ERP Systems Choice. Accounting Horizons, v. 23, n. 4, p. 365-389, 2009.

VAN DER STEEN, M. The emergence and change of management accounting routines. Accounting, Auditing \& Accountability Journal, v. 24, n. 4, p. 502-547, 2011.

WANDERLEY, C.; CULLEN, J. Mudanças na Contabilidade gerencial: uma revisão. BASE Revista de Administração e Contabilidade da Unisinos, v. 10, n. 4, 2013.

WHITTLE, A.; CARTER, C.; MUELLER, F. 'Above the fray': Interests, discourse and legitimacy in the audit field. Critical Perspectives on Accounting, v. 25, n. 8, p. 783-802, 2014.

YANG, C.; MODELL, S. Power and performance. Accounting, Auditing \& Accountability Journal, v. 26, n. 1, p. 101-132, 2012.

ZUCCOLOTTO, R.; SILVA, G.M.; EMMENDOERFER, M. Limitações e possibilidades de compreensão da utilização das práticas de Contabilidade Gerencial por perspectivas da Teoria Institucional. BASE - Revista de Administração e Contabilidade da Unisinos, v. 7, n. 3, 2010.

Data de Submissão: 15/10/2016.

Data de Aprovação: 27/11/2017. 